\title{
OCCURRENCE OF EXTENSILE CRACKS IN COHESIVE SOILS DUE TO COMPRESSION
}

\author{
SHIN-ICHI NISHIMURA ${ }^{\mathrm{i})}$
}

\begin{abstract}
It is a generally accepted fact that tensile failure takes precedence over shear failure when a material is transformed from a ductile state into a brittle one. In order to evaluate the growth of extensile cracks, two series of compression tests with samples from volcanic cohesive soil obtained from a low fill dam were performed. Results show that extensile cracks may generate prior to shear failure when the friction between the specimen and the pedestal was reduced. Under such circumstances, compressive strength does not decrease until the shearing cracks are generated. This is the same in the case when a confining pressure is acting. In a test using a composite specimen made of two samples of different water contents, extensile cracks occurred at the portion with a low water content. The compressive stress at the time when the extensile crack occurred was lower than that in the case of the low water content specimen. Moreover, finite element analysis was performed to calculate the stresses in the specimens at the generation of extensile crack. Results shows that the horizontal stresses that exerted on the crack surfaces were not tensile but compressive in the case when a confining pressure was acting.
\end{abstract}

Key words: crack, extensile strain, finite element method, tri-axial test, volcanic cohesive soil (IGC: D0)

\section{INTRODUCTION}

Hydraulic fracturing is considered to be one of the causes of leakage or collapse of fill-type dams and is induced by cracks in a dam body or foundation. The foundation is extended in the horizontal direction partially when an embankment is constructed. This extension can induce vertical cracks in the foundation. Since the horizontal earth pressure is generally less than the vertical earth pressure, vertical cracks can easily develop into hydraulic fracture. Therefore, it is important to investigate the growth of vertical cracks due to the horizontal extension (hereafter: extensile cracks) in dam bodies or foundations.

It is a generally accepted fact that development of tensile crack gives priority over shear crack when a material is transformed from a ductile state into a brittle one. Therefore, the occurrence of extensile cracks is considered to be brittle even in clayey soils. Janbu (1979) also showed that tension cracks are always associated with tensile strains, but not necessarily with tensile stress.

In order to evaluate the growth of extensile cracks in dam bodies or foundations, it is important to confirm the occurrence of extensile cracks by a compression test. We have performed two series of compression tests with samples of volcanic cohesive soil obtained from a soft foundation of a low fill dam. One was with an undisturbed sample and the other was with a disturbed sample. Whether the same extensile cracks as those in rocks would occur or not were observed when the friction on the top and bottom surfaces of a specimen using the undisturbed sample was excluded. In the test carried out with the disturbed sample, it was examined whether extensile cracks occurred due to the advancement of a brittle state as a result of the decrease in water content of the sample. Through these tests, the occurrence of extensile cracks (due to the horizontal extension by compressing in the vertical direction) and shear cracks was examined.

\section{FAILURE IN COMPRESSION TEST}

It is known that vertical cracks (Fig. 1(a)) occur during the compression test of homogeneous hard rocks if the friction on the top and bottom surfaces of the specimen is reduced. Shear failure (Fig. 1(b)) occurs when cones were generated (active region: the dotted line in Fig. 1 (b)) by the friction between a specimen and pedestals (The Japanese Geotechnical Society, 1974). It is considered that this phenomenon is due to the brittleness of rocks. Janbu (1979) described that, when the element of Fig. 2 undergoes deformation at approximately constant volume (i.e. the $\sigma_{1}$-axis shortens while the $\sigma_{3}$-axis expands), it may generate cracks in the $\sigma_{1}$-direction due to tensile strain in the $\sigma_{3}$-direction. He also pointed out that tensile strain cracks occur earlier than shear cracks,

i) Associate Professor, Faculty of Applied Biological Sciences, Gifu University, 1-1, Yanagido, Gifu 501-1193, Japan (Nisimura@cc.gifuu.ac.jp).

The manuscript for this paper was received for review on August 29, 2003; approved on January 4, 2005.

Written discussions on this paper should be submitted before January 1, 2006 to the Japanese Geotechnical Society, 4-38-2, Sengoku, Bunkyo$\mathrm{ku}$, Tokyo 112-0011, Japan. Upon request the closing date may be extended one month. 


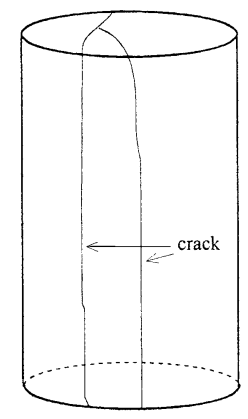

(a)

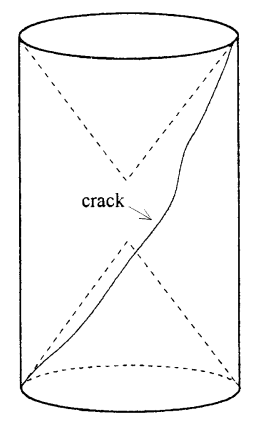

(b)
Fig. 1. Destruction of a rock

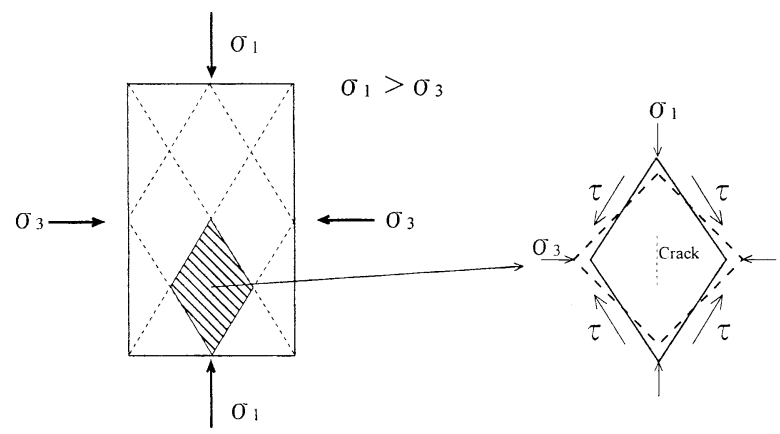

Fig. 2. Tensile crack resulting from compression

and they occur under the compressive stress. It is therefore considered that extensile cracks occur not only due to the tensile stress but also extensile strains.

\section{COMPRESSION TEST FOR THE UNDISTURBED SOIL}

\section{Objectives of the Test}

When the friction at the top and bottom surfaces of a specimen is reduced as much as possible, it is possible to determine whether vertical cracks by horizontal extension occur earlier than shear cracks in the undisturbed sample comparatively brittle. Moreover, by comparing the stress at the occurrence of extensile cracks with that at the occurrence of shear cracks, the generated condition of extensile cracks is examined.

\section{Specimens Used in the Test}

The undisturbed sample for specimens was soft pyroclastic ash loam $(N$ value $<5)$ which was obtained from a pits dug (depth of 1-2 $\mathrm{m}$ ) in the foundation of a low fill dam with the embankment perimeter of $1780 \mathrm{~m}$, located in Tsunan town in the southern part of Niigata Prefecture. Table 1 lists physical properties of the undisturbed sample. This sample was molded in the shape of a cylindrical specimen of diameter $5.0 \mathrm{~cm}$ and height $8.0 \mathrm{~cm}$ (We have made the height $8.0 \mathrm{~cm}$ to cut out as much specimens as possible from the shape of the specimen due to its small size). To change the influence of
Table 1. Physical properties of sample

\begin{tabular}{c|c}
\hline \multicolumn{1}{c|}{ Items } & \\
\hline Particle density $\left(\mathrm{g} / \mathrm{cm}^{3}\right)$ & 2.72 \\
\hline Liquid limit $(\%)$ & $110 \sim 150$ \\
\hline Plastic limit $(\%)$ & $60 \sim 80$ \\
\hline Grain size distribution & 15 \\
\hline Sand $(\%)$ & 15 \\
\hline Silt $(\%)$ & 70 \\
\hline Clay $(\%)$ & $0.95 \sim 0.97$ \\
\hline Maximum dry density $\left(\mathrm{g} / \mathrm{cm}^{3}\right)$ & $1.56 \sim 1.62$ \\
\hline Wet density $\left(\mathrm{g} / \mathrm{cm}^{3}\right)$ & $70 \sim 100$ \\
\hline Water content $(\%)$ & $93 \sim 95$ \\
\hline Degree of saturation $(\%)$ & \\
\hline
\end{tabular}

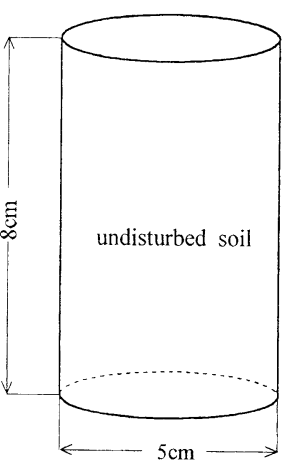

(a):Method A

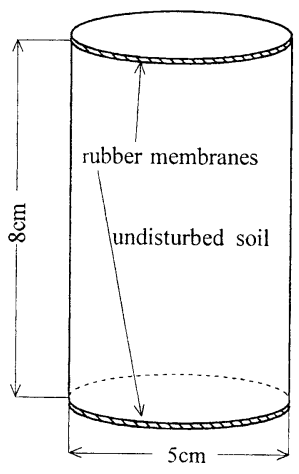

(b):Method B
Fig. 3. Undisturbed soil specimens used for the compression tests

the friction along the top and bottom surfaces of the specimen, two kinds of experimental conditions were set. The one shown in Fig. 3((a): Method A) for the observation of shear cracks and the determination of shear strength has no rubber membranes. The other, illustrated in Fig. 3((b): Method B) is for the observation of extensile cracks and has rubber membranes spread with grease at the top and bottom faces for the reduction of friction between the specimen and pedestals.

\section{Experimental Method}

Compression tests were performed in unconsolidated and undrained condition and the rate of compression was approximately $1.0 \mathrm{~mm} / \mathrm{min}$, which is the fastest rate using the compressor available. The purpose of the tests is to examine whether extensile cracks precede shear cracks even on this type of soil. The fastest compression speed shortens the test time under the unconsolidated and undrained condition. The influence of water drainage is considered to be small when a soil with hydraulic conductivity of about $10^{-6} \mathrm{~cm} / \mathrm{s}$ is compressed in a short time.

It was assumed that the sample was normally consolidated because the site where the samples were collected 


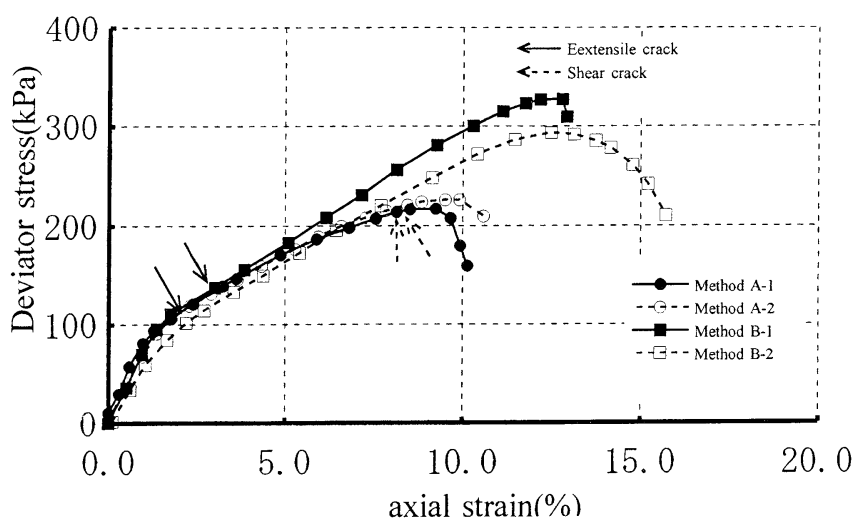

Fig. 4. Relationship between stress and strain $\left(\sigma_{3}=0 \mathrm{kPa}\right)$

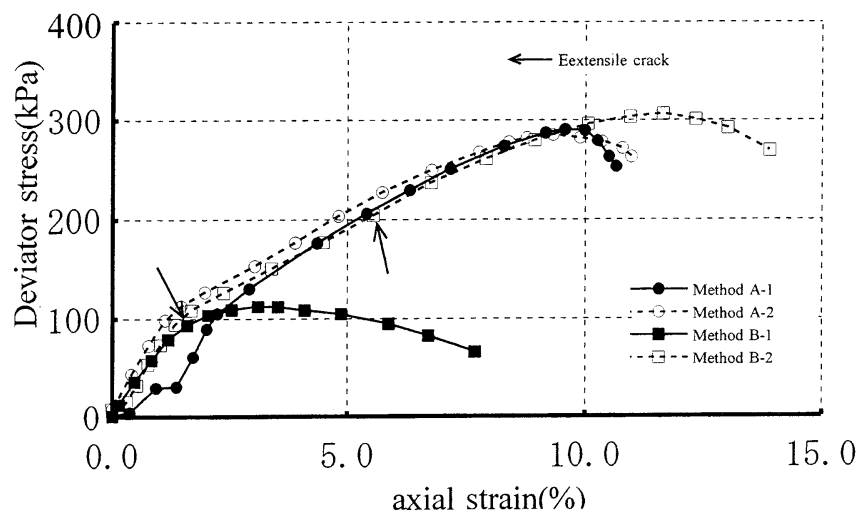

Fig. 5. Relationship between stress and strain $\left(\sigma_{3}=9.8 \mathrm{kPa}\right)$

had been dug up and buried again several years ago. Its Poisson's ratio $(v)$ and moist density were 0.3 and $1.4 \mathrm{Mg} / \mathrm{m}^{3}$ respectively. The horizontal earth pressure at 2 m-depth was about $12.0(=0.3 /(1-0.3) \cdot 2 \cdot 1.4) \mathrm{kPa}$ if the coefficient of earth pressure at rest is assumed to be $v /(1-v)$. In addition, a confining pressure of $9.8 \mathrm{kPa}$ $\left(0.1 \mathrm{kgf} / \mathrm{cm}^{2}\right)$ was applied to the specimens. This value is close to the assumed horizontal earth pressure of $12 \mathrm{kPa}$, because the minimum scale of a pressure gauge was $9.8 \mathrm{kPa}\left(0.1 \mathrm{kgf} / \mathrm{cm}^{2}\right)$.

\section{Experimental Results}

The compression tests were performed experiments under lateral pressures of $0 \mathrm{kPa}$ and $9.8 \mathrm{kPa}$, using a total of four specimens (two each in Method A and Method B) at each pressure. Figures 4 and 5 show the relationship between deviator stress and axial strain, and Photos 1 4 show the state of the specimens during or after the experiments with each method. The arrows in Figs. $4 \sim 6$ are the points corresponding to the time when cracks were confirmed by visual.

With Method B vertical cracks (referred to as the extensile crack hereafter because of the extension in the horizontal direction) occurred at the axial stress of approximately $100 \mathrm{kPa}$ (Figs. 4 and 5) as shown in Photos 2 and 4. Subsequently, a shear crack (Photo 1) occurred

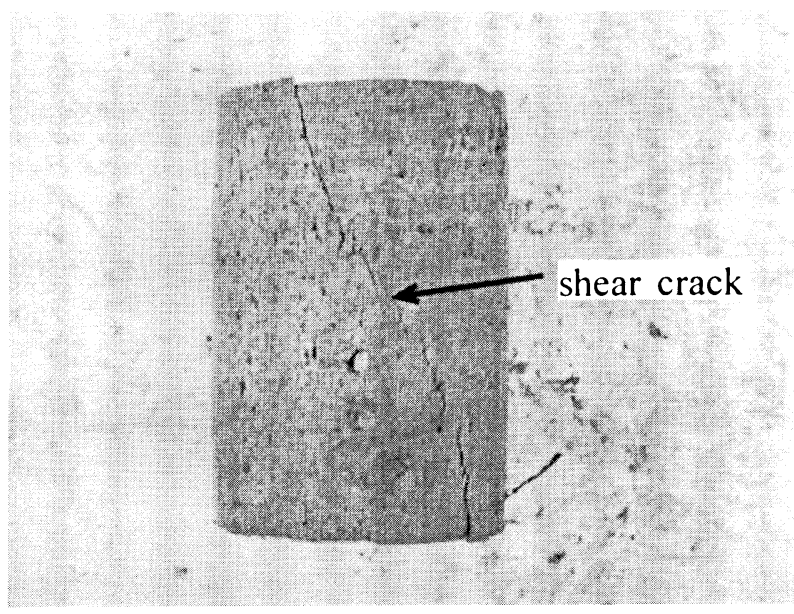

Photo 1. Method A $\left(\sigma_{3}=0 \mathrm{kPa}\right)$

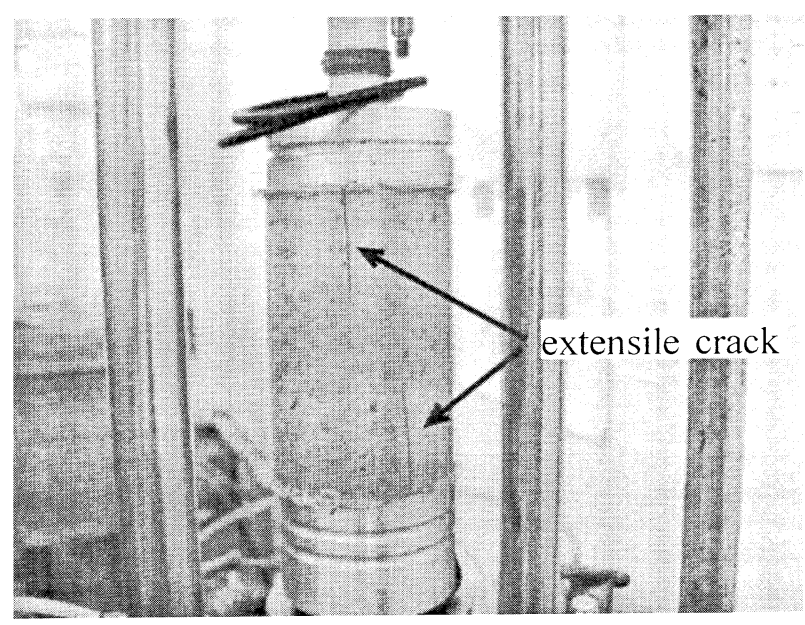

Photo 2. Method B $\left(\sigma_{3}=0 \mathrm{kPa}\right)$

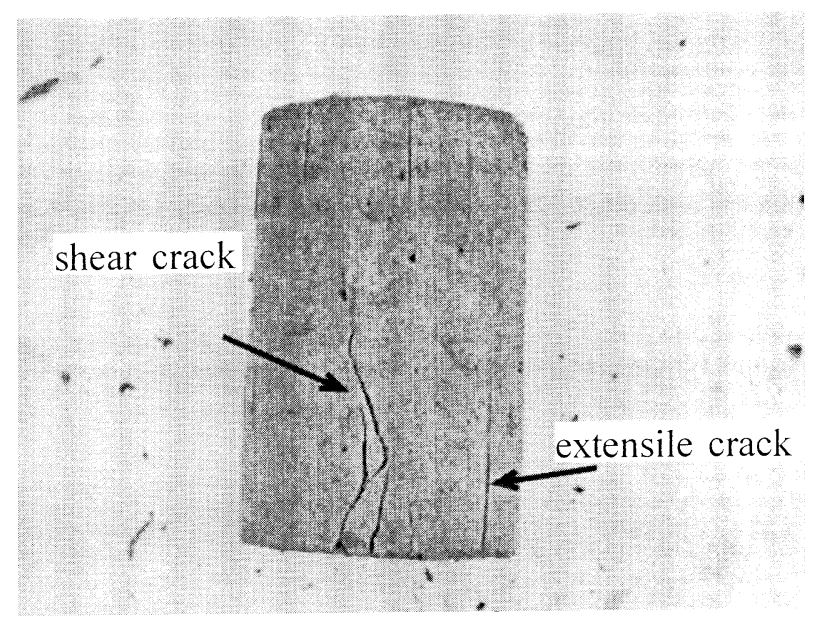

Photo 3. Method A $\left(\sigma_{3}=9.8 \mathrm{kPa}\right)$

just before the stress decreased. For an undisturbed sample, it is probable that extensile cracks occurred earlier than shear cracks when the friction at the specimen boundary is small. The extensile crack in Photo 3 was 


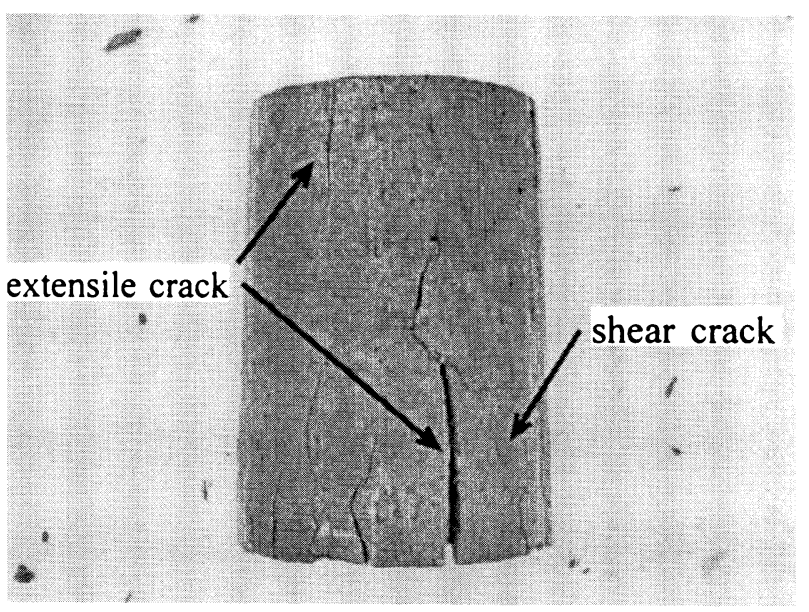

Photo 4. Method $\mathrm{B}\left(\sigma_{3}=9.8 \mathrm{kPa}\right)$

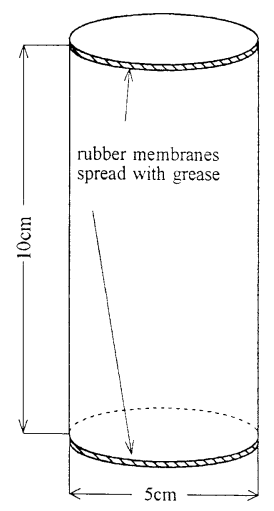

(a):Specimen A

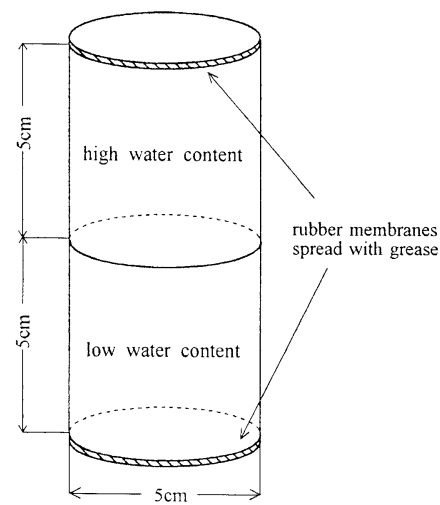

(b):Specimen B

Fig. 6. Disturbed soil specimens used for the compression tests

almost simultaneously observed when the shear crack occurred. Moreover, the shear crack shown in Photo 4 occurred as the result of the load increase after the extensile crack had been observed.

In addition, the stress-strain curves of Method $\mathrm{A}$ and Method B show an almost similar trend except Method B-1 in Fig. 5, and it therefore seems that the extensile cracks do not influence the compressive strength significantly. As for Method B-1, it is likely that the strength has decreased compared to that of the other specimens because it partially included anomalous substances such as vegetable roots. Therefore, it is possible that the fill-type dam constructed with the sample has not been destroyed in terms of supporting the load, but it has been occasionally destroyed in terms of water storing potential.

\section{COMPRESSION TEST FOR THE DISTURBED SOIL}

Objectives of the Test

With the undisturbed samples, extensile cracks occurred earlier than shear cracks in the compression test under the low friction boundary condition. Consequently, it is possible that extensile cracks can occur

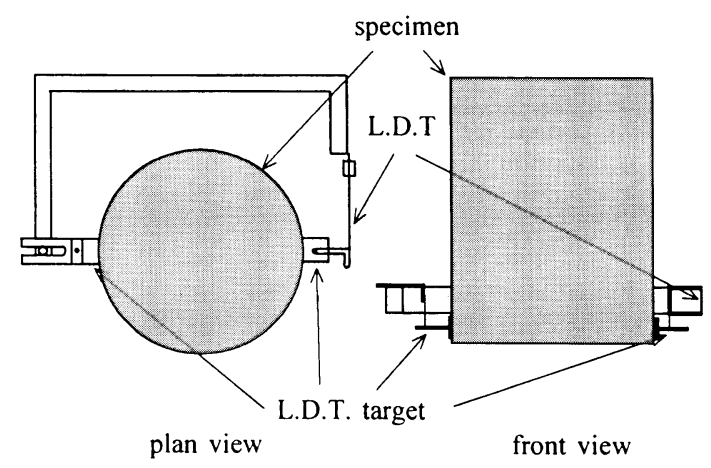

Fig. 7. L.D.T. used for the compression tests

during the compression test on the disturbed soil as it undergoes the change from a ductile state into a brittle one due to the decrease in water content. Therefore, the occurrence of extensile cracks or shear cracks was examined with disturbed specimens of varying water contents. Moreover, the occurrence of the cracks was also examined in a situation when two specimens with different water contents were stacked. In this experiment, the initial water content of the sample was gradually decreased from $70 \%$ to $50 \%$ and the degree of saturation was $97 \sim 100 \%$.

\section{Experimental Method}

Specimens were prepared by compacting the sample with 25 blows of a $4.5 \mathrm{~kg}$ weight rammer separately in five layers using a $10 \mathrm{~cm}$ diameter mold and trimming with a wire saw like the column of $10 \mathrm{~cm}$ in height and $5 \mathrm{~cm}$ in diameter (Fig. 6: Specimen A). Using the specimens, the change crack development due to the variation in the water content was observed and the stress-strain relationship was determined.

Moreover, a composite specimen of $10 \mathrm{~cm}$ height (Fig. 6: Specimen B) was made by mounting a specimen of $5 \mathrm{~cm}$ height and $5 \mathrm{~cm}$ diameter on top of the other with same dimensions. These specimens had different water contents of about $70 \%$ and about $50 \% \sim 60 \%$. Using the specimens, crack development of the composite specimen was observed and the elastic moduli were measured. Experiments on both specimens were conducted with the same apparatus and rubber membranes were used as described earlier. The condition of the experiments was assumed as unconsolidated and undrained. The rate of compression was about $1.0 \mathrm{~min} / \mathrm{s}$ and the confining pressure was set at either 0.0 or $9.8 \mathrm{kPa}$. The horizontal displacement was determined using L.D.T. (Local Deformation Transducer: Goto et al., 1991) to find the extensile strain when extensile cracks occur. Figure 7 shows how the L.D.T. device was attached to the specimen.

\section{Experimental Results}

The Case without Confining Pressure

Extensile cracks (shown in Photo 5) occurred in specimen A ahead of the shear cracks at a time when 
water content had decreased to about $60 \%$. As the water content decreased, the specimen became more brittle resulting in the occurrence of cracks. Figure 8 shows the stress-axial strain curves of specimen $\mathrm{A}$ when the water content is $50.6 \%$ and $65.8 \%$. The $65.8 \%$ case does not show any extensile cracks, but the increase rate of the deviator stress has decreased after shear cracks occurred.

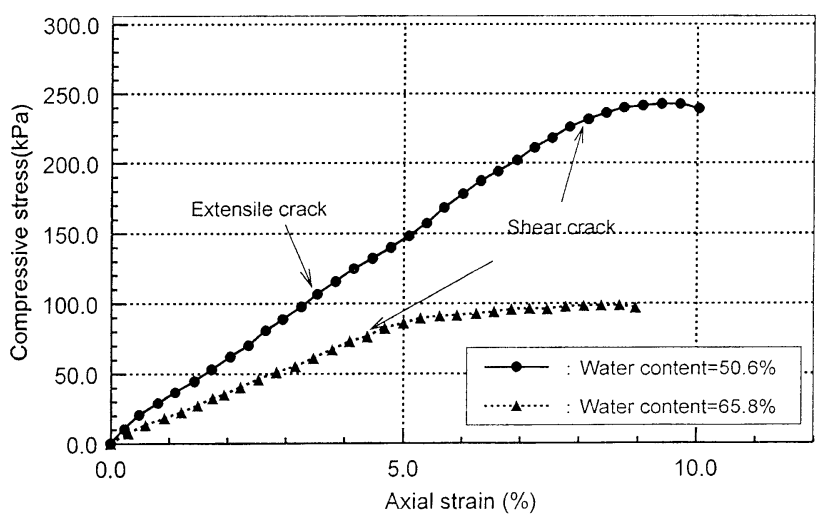

Fig. 8. Relationship between extensile strain and compressive stress (Specimen A, $\sigma_{3}=\mathbf{0} \mathbf{~ P a}$ )

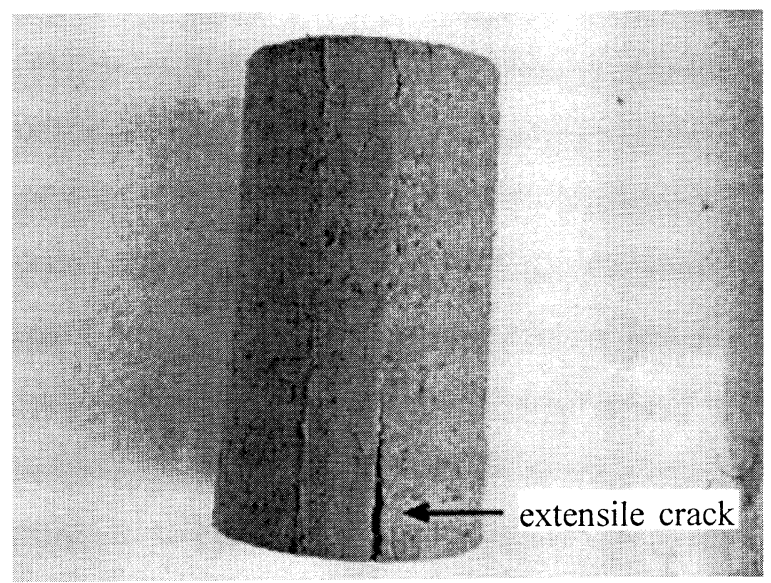

Photo 5. Specimen A $\left(\sigma_{3}=0 \mathrm{kPa}\right)$
The $50.6 \%$ case shows some extensile cracks with the load of about $106 \mathrm{kPa}$, but the increase rate of the deviator stress has also decreased after shear cracks occurred as in the $65.8 \%$ case. In the case of $50.6 \%$ water content, extensile cracks occurred earlier than shear cracks and did not influence the strength of the specimen, as in the undisturbed samples.

One of the compressive stresses-axial strain curves of specimen B is shown in Fig. 9. As in the case of specimen A, the compressive stress did not decrease even when extensile cracks occurred in the lower part of specimen B. Photo 6 shows specimen B after the compression test. Extensile cracks were observed in the part with a lower water content. Since the elastic modulus of the portion with a higher water content was smaller than the portion with a lower water content, the latter was stretched by the upper part and extensile cracks occurred. Compressive stresses and extensile strains at the instant when extensile cracks occurred in the two specimens (specimen $\mathrm{A}$ and specimen B (the portion with low water content)) are shown in Figs. 10 and 11 respectively as a function of water content.

There is a tendency for to increase compressive stresses (Fig. 10) when extensile cracks initiated as the water

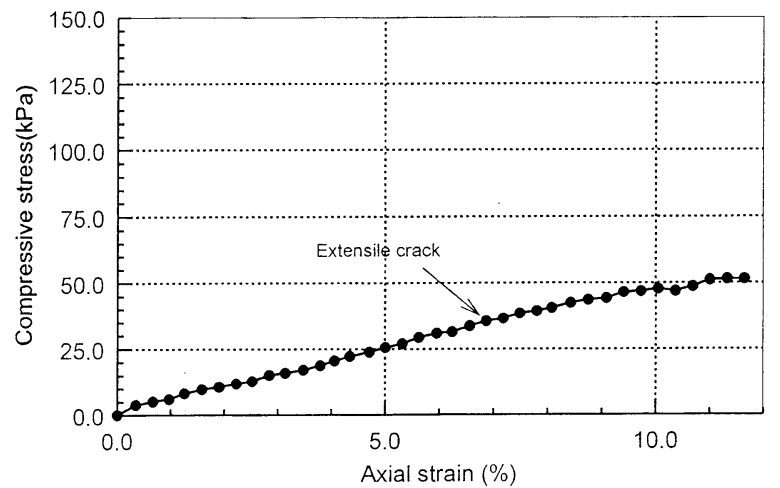

Fig. 9. Relationship between extensile strain and compressive stress (Specimen B, $\sigma_{3}=0.0 \mathrm{kPa}$ )

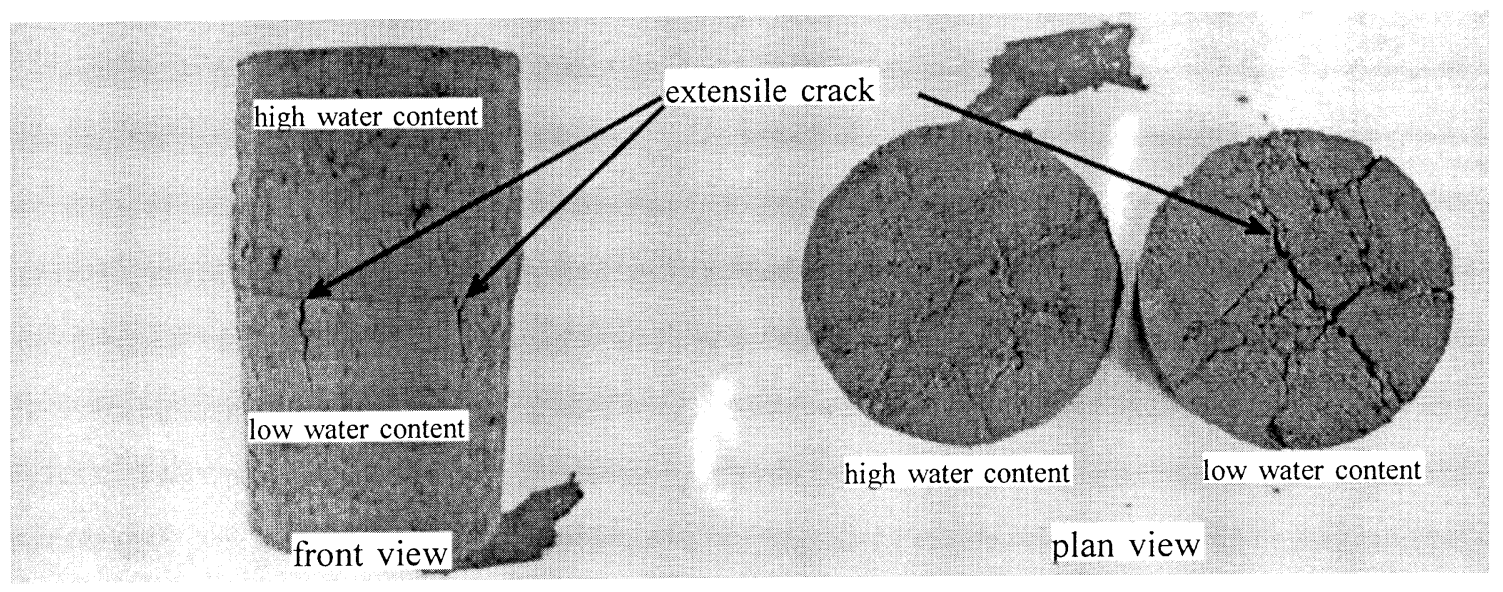

Photo 6. Specimen $\mathrm{B}\left(\sigma_{3}=0 \mathrm{kPa}\right)$ 


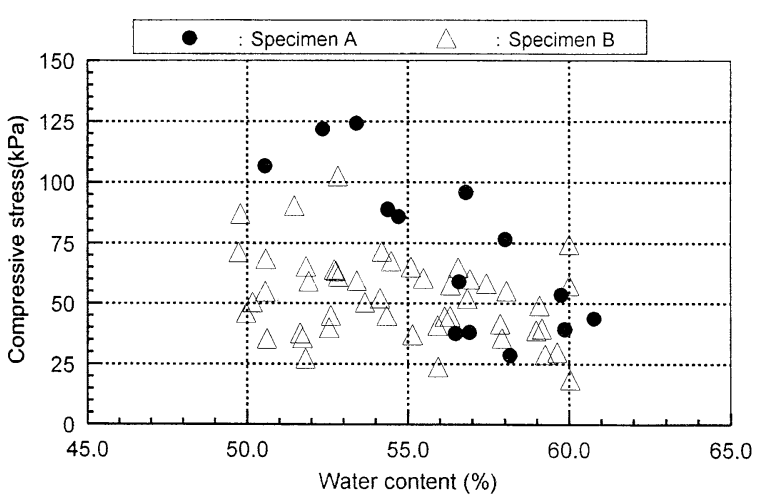

Fig. 10. Relationship between compressive stress and water content when extensile crack occurs $\left(\sigma_{3}=0 \mathrm{kPa}\right)$

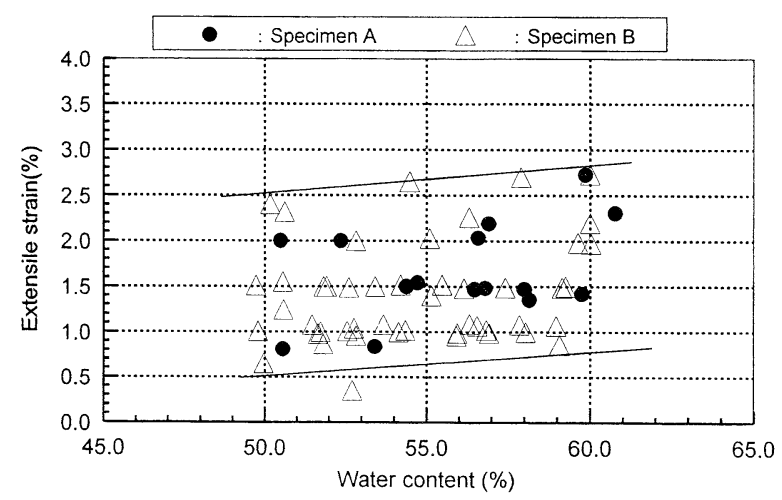

Fig. 11. Relationship between extensile strain and water content when extensile crack occurs $\left(\sigma_{3}=0 \mathrm{kPa}\right)$

content decreased. On the other hand, the tendency of extensile strains (Fig. 11) decreased slightly as water content decreased. Hence there is a possibility that the strain at which extensile cracks occur becomes small with the decrease of water content and the degree of brittleness. If the water content of two specimens is the same, the compressive stress that induced the extensile crack in specimen B is likely to have a low value compared with compressive stress that induced the extensile crack in specimen A as illustrated in Fig. 10. This trend is clearer as the water content decreases. On the other hand, Fig. 11 shows that, if the water contents are the same, the extensile strains of both specimens may have a similar value. Presumably, the extensile cracks were caused by low compressive stresses in specimen B compared with specimen A because the hard part (lower part of specimen B) is laterally stretched by the soft part (upper part of specimen B).

\section{The Case with $9.8 \mathrm{kPa}$ Confining Pressure}

When the confining pressure was added, the generated extensile crack could not be confirmed easily because of the rubber sleeve with which the specimen was covered. Therefore, it was necessary to check the cracks by removing the rubber sleeve from the specimen after it reached the lateral strains to some extent. It was found that the

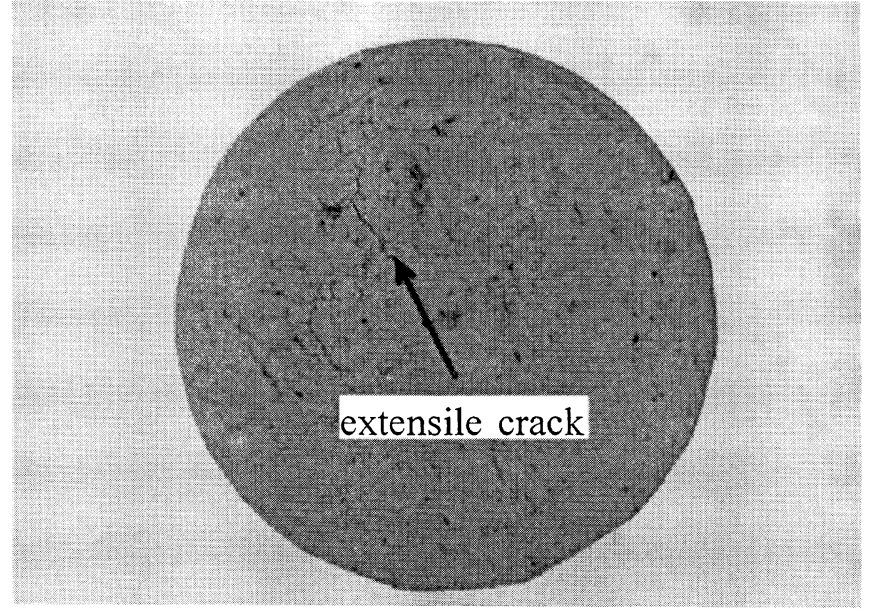

Photo 7. Specimen A $\left(\sigma_{3}=9.8 \mathrm{kPa}\right)$

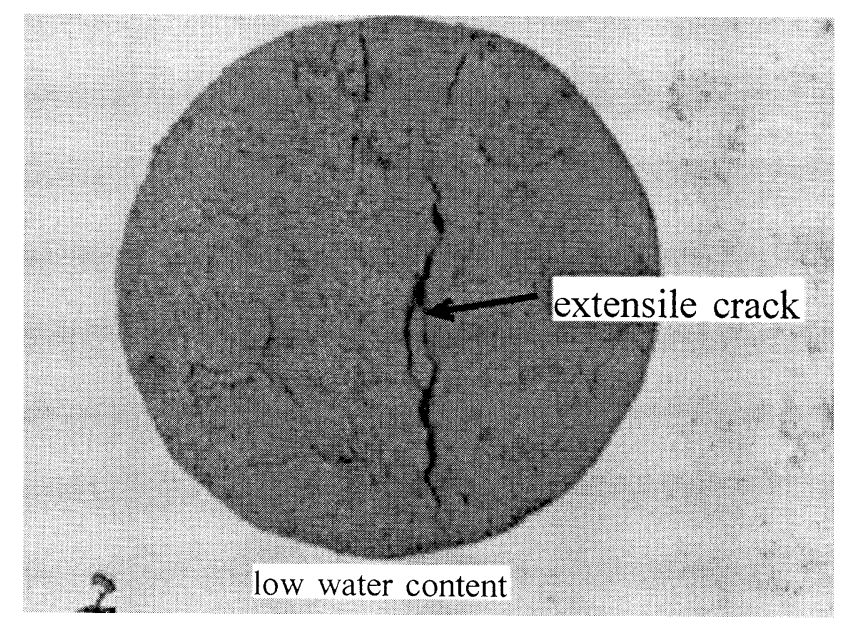

Photo 8. Specimen B $\left(\sigma_{3}=9.8 \mathrm{kPa}\right)$

cracks hardly occurred when extensile strains are less than $0.5 \%$. Therefore, three specimens of the same water content were used. The occurrence of extensile cracks was confirmed in each specimen when extensile strains of each one reached $1.0,1.5$, and $2.0 \%$ respectively. The extensile cracks that occurred in specimen $\mathrm{A}$ and specimen $\mathrm{B}$ are shown in Photo 7 and Photo 8 respectively. Moreover, the deviator stresses and extensile strain at the instant when extensile cracks occurred in the two specimens (specimen A and specimen B (the portion with low water content)) are shown in Figs. 12 and 13 respectively as a function of water content. The extensile crack was confirmed in both specimens, but the extensile crack that developed in specimen B was plainer than that of specimen A because of the lateral extension of the higher water content section. When compared to the case of which lateral pressure was $0 \mathrm{kPa}$, the width of the cracks was larger and more distinctive in both specimen $\mathrm{A}$ and specimen $\mathrm{B}$ in the $0 \mathrm{kPa}$ case with no restraint from the side. However, a large crack was seen almost at the center of the specimen in both cases. The deviator stresses in 


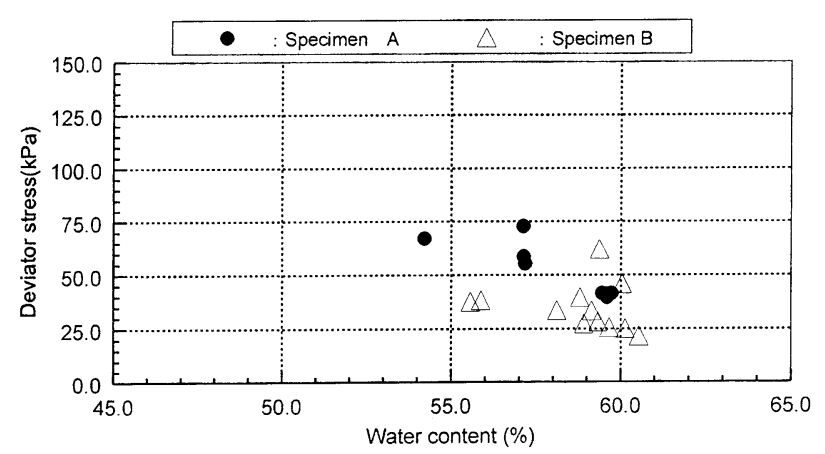

Fig. 12. Relationship between deviator stress and water content when extensile crack occurs $\left(\sigma_{3}=9.8 \mathrm{kPa}\right)$

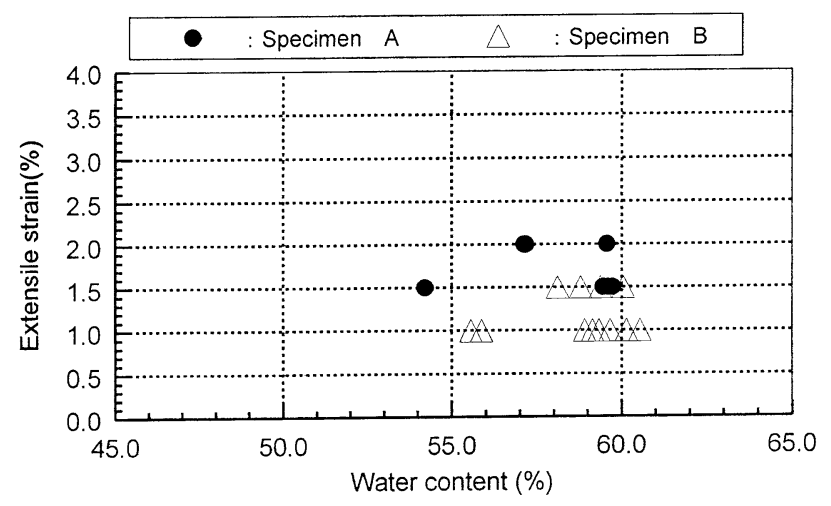

Fig. 13. Relationship between extensile strain and water content when extensile crack occurs $\left(\sigma_{3}=9.8 \mathrm{kPa}\right)$

specimen A when the extensile cracks occurred are larger than those in specimen $\mathrm{B}$ and the range and the values are similar to the case where there was no confining pressure. Moreover, because there were only three magnitudes of extensile strains $(1.0,1.5$, and $2.0 \%)$, the tendency was not clear but the range is, of what is similar to the case without confining pressure. The occurrence of extensile cracks under the compressive stress was successfully verified by this experiment.

\section{FEM ANALYSIS FOR THE SPECIMEN OF TWO LAYERS}

\section{Objectives of the Analysis}

It was confirmed in the compression test using a soil specimen that a vertical extensile crack occurred by the compression in the vertical direction by applying to a low friction boundary condition. Although the horizontal strain (= displacement of diameter/diameter) of the specimen was measured in the experiments, the horizontal stress of disturbed soil specimen B could not be determined. Therefore, the stresses that act on the contact surfaces of specimen B were calculated by FEM analysis.

\section{Method of the Analysis}

Since the load was below the shear strength when

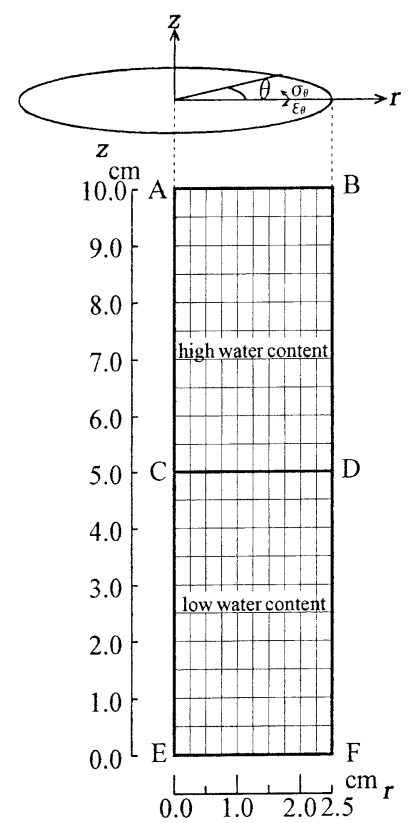

Fig. 14. FEM model for the analysis

cracks developed, linear elasticity was assumed and the axisymmetric model (Fig. 14) by cylindrical coordinates and quadratic quadrilateral element was adopted. The actual specimen is not always even and hence deformation and stress distribution cannot be exactly axisymmetric. However, they were made axisymmetric because it was not possible to consider the unevenness in the present $2 \mathrm{D}$ analysis.

In Fig. 14, AE was assumed as the axis of symmetry, the displacement in the vertical direction of boundary EF was fixed and the load was made to act on boundary AB. Elastic modulus (bottom portion of specimen $=$ $0.70 \sim 1.27 \mathrm{MPa}$, top portion of specimen $=0.35 \sim 0.85$ $\mathrm{MPa})$ and Poisson's ratio $(v)$ of specimen $\mathrm{B}$ were determined by the experimental results. Poisson's ratio ( $v$ ) was separately measured using gap sensors for axial displacement and LTD for lateral displacement. As a result, for the range of water content varied in the experiments, the value of $v$ decreased slightly with the decrease in water content. However, $v=0.35$ was set because the measured values were in the range of $0.35 \pm 0.05$. A separate analysis was performed by making Poisson's ratio of the lower part 0.3 and that of the upper part 0.4 . It was found that the result was the same as in the case with Poisson's ratio $=0.35$ for both parts.

\section{Results of the Analysis}

The top surface of the lower part of a specimen (low water content part) (CD in Fig. 14) was examined because extensile cracks occurred in the low water content part in the experiments. The direction of stress by which extensile cracks occur is in the direction of $\theta$ (in Fig. 14), and therefore circumferential stresses $\sigma_{\theta}$ on CD line of the low water content part were calculated. Figure 15 shows the relationship between $r$ (distance from the 


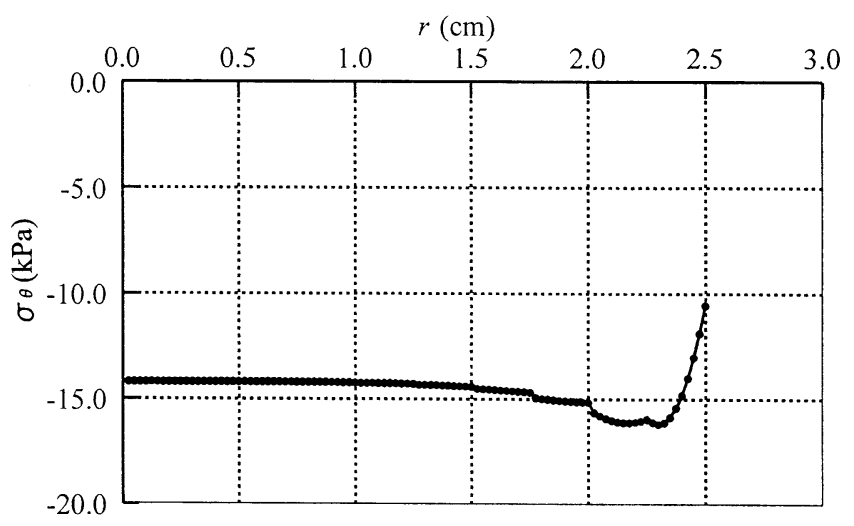

Fig. 15. Calculated $\sigma_{\theta}$ when tensile crack occurs in specimen B

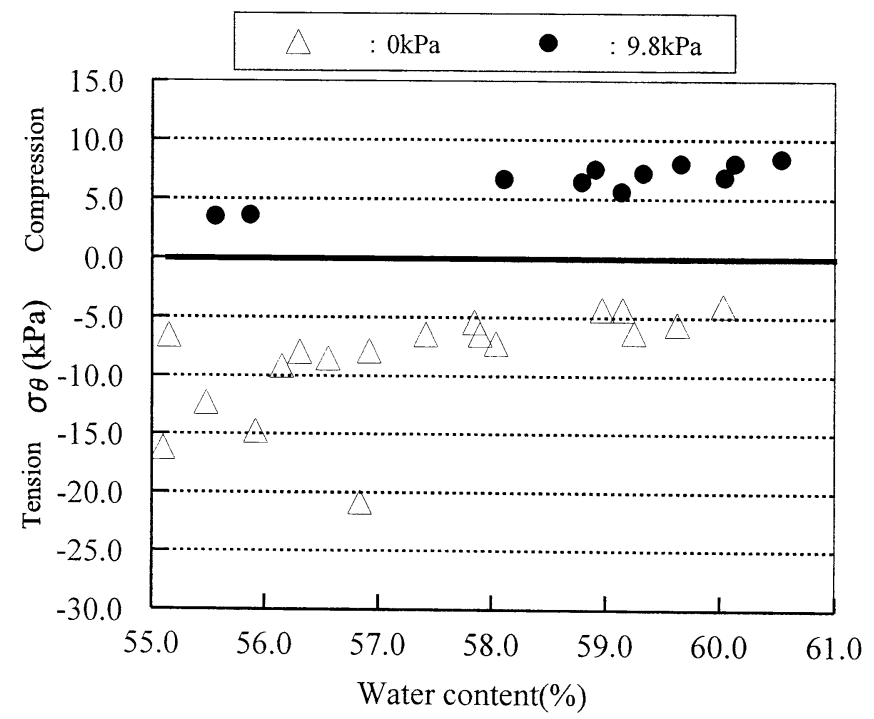

Fig. 16. Calculated $\sigma_{\theta \min }$ when tensile cracks occur in specimen B

center of specimen) and $\sigma_{\theta}$ in the cases where water contents of upper and lower parts of the specimen were $67.4 \%$ and $55.1 \%$ respectively and the confining pressure was $0 \mathrm{kPa}$. Circumferential stress almost remains a constant value from $r=0 \mathrm{~cm}$ to about $r=1.5 \mathrm{~cm}$ and becomes of minimum value at $r=2.3 \mathrm{~cm}$. Then the value increases a maximum value as it approaches the side surface of the specimen. If the extensile crack is caused by the tensile stress it is thought that the extensile crack is generated when the tensile stresses exceed the tensile strength. Figure 16 shows the minimum circumferential stresses $\left(\sigma_{\theta \min }\right)$ when the water contents of the lower parts of specimens are $55-60 \%$, and the confining pressure is $0 \mathrm{kPa}$ or $9.8 \mathrm{kPa}$. The minimum circumferential stresses under $0 \mathrm{kPa}$ confining pressure were tensile but those under the $9.8 \mathrm{kPa}$ confining pressure were compressive. Therefore, it is thought that the extensile crack will occur even if under the compressive stress, because microscopically there is a possibility that the tensile stress will act at particle contact. It is believed that the generation of extensile cracks cannot be expected by only the distribution of stress obtained by FEM.

By reasoning that the extensile crack has been generated when some extensile strain is caused according to the experimental result in the preceding sections, it seems that the magnitude of strain can be used as a determining factor of the generation of extensile cracks.

The stress state of tested specimens is relatively easy and is different from that in the ground of actual foundation and embankment. Therefore, it is necessary to examine and analyze under more realistic conditions to reproduce a better state of the field.

\section{CONCLUSIONS}

1. It is possible that extensile cracks occur earlier than shear cracks by compressing in the perpendicular direction when the soil is brittle. This is similar to the case when confining pressure of $9.8 \mathrm{kPa}$ was acting.

2. There is no decrease in strength even if extensile cracks are generated in the specimen. On the other hand, the strength decreased when shear cracks formed.

3. When a specimen with a low elastic modulus was added on top of a specimen with a high elastic modulus, the latter was extended to the side by the expansion of the former as the combined specimen was compressed. For the composite specimens, extensile cracks were generated by a relatively small load compared to the case of the specimen which consists of only the soil with a large elastic modulus.

4. Although the stress causing extensile cracks differs depending on the confining pressure, the strains that generated cracks were about the same.

5. When ductile clay is filled as an embankment to a brittle foundation, it is possible that extensile cracks would occur in the foundation by the lateral movement of the embankment. Moreover, the load by which extensile cracks could occur is considerably smaller compared to the shearing strength. Therefore, it is necessary to thoroughly examine the generation of extensile cracks that may cause hydraulic fracturing by the stress and strain of the foundations and embankments.

\section{REFERENCES}

1) Goto, S., Tatsuoka, F., Shibuuya, S., Kim, Y.-S. and Sato, T. (1991): A simple gauge for local small strain measurements in the laboratory, Soils and Foundations, 31 (1), 169-180.

2) Janbu, N. (1979): Mechanisms of failure in natural and artificial soil structures, Int. Symp. on Soil Mechanics, Oaxca, Mexico, 1, 95-124.

3) The Japanese Geotechnical Society (1974): Iwa no Kougakuteki Seishisu to Sekkei eno Ouyou, 118. 